Article

\title{
Developing Sustainable Workplaces with Leadership: Feedback about Organizational Working Conditions to Support Leaders in Health-Promoting Behavior
}

\author{
Paul Jiménez* ${ }^{\mathbb{D}}$, Bianca Winkler and Anita Bregenzer \\ Department of Psychology, University of Graz, 8010 Graz, Austria; bianca.winkler@alumni.uni-graz.at (B.W.); \\ anita.bregenzer@uni-graz.at (A.B.) \\ * Correspondence: paul.jimenez @uni-graz.at; Tel.: +43-316-380-5128
}

Received: 27 September 2017; Accepted: 21 October 2017; Published: 26 October 2017

\begin{abstract}
Organizations should support leaders in promoting their employees' health in every possible way to achieve a sustainable workplace. A good way to support leaders could include getting feedback about their health-promoting behavior from their employees. The present study introduces an instrument (Health-Promoting Leadership Conditions; HPLC) that enables the provision of feedback about the leaders' efforts to create health-promoting working conditions in seven key aspects: health awareness, workload, control, reward, community, fairness and value-fit. The instrument was used in employee surveys and in an online study, obtaining a sample of 430 participants. The results showed that all seven key aspects of health-promoting leadership can be assigned to a main factor of health-promoting leadership. In addition, the HPLC shows high construct validity with dimensions of stress, resources and burnout (Recovery-Stress- Questionnaire for Work [RESTQ-Work] and Maslach Burnout Inventory General Survey [MBI-GS]). The results indicate that the HPLC can be used as a basis on which to assess health-promoting leadership behavior with a focus on changing working conditions. By getting feedback about their leadership behavior from their employees, leaders can identify their potential and fields for improvement for supporting their employees' health and developing a sustainable workplace.
\end{abstract}

Keywords: health; leadership; stress; working conditions; workplace health promotion

\section{Introduction}

Sustainability at the workplace encompasses not only sustainability in terms of the ecological or socio-economic working environment but also encompasses the improvement of well-being for all employees [1]. Sustainability at the workplace should go beyond social and environmental responsibility and should include all management processes that aim at creating long-term well-being [2]. To develop a sustainable workplace, leaders are needed that engage in leadership behavior aimed at supporting the health of their employees in the long term [1]. A healthy workplace that is sustainable can be best achieved by changing organizational factors, such as critical working conditions [3]. Leaders are able to manage and rearrange critical working conditions at the workplace with their behavior [4].

The management of the organization should support the leaders' efforts in promoting health at the workplace in every possible way. A possible approach to support leaders in creating a sustainable workplace could involve feedback-tools that allow leaders to monitor their leadership behavior and improve their behavior if necessary. By getting feedback on their leadership behavior from their employees, leaders can find out about their leadership potential and address fields for improvement [5]. Feedback-tools in leadership have a long tradition when it comes to more "traditional" leadership 
tasks such as management or interpersonal behavior [6] but can be used to monitor efforts in health-promoting behavior as well.

Leadership in health promotion typically focuses on the leader as the responsible factor which (a) directly influences the health of the employee or (b) changes the work environment which has an effect on the health of all people. This understanding puts a heavy burden on the shoulders of leaders. This has to be addressed in view of modern Workplace Health Promotion (WHP). WHP should address the right questions to achieve health by obtaining a healthy work environment in the organization according to the Luxembourg declaration [7]. As leaders have a significant influence on the workplace and their employees this is "one of the most important workplace relationships with implications for individual well-being" [8], p. 262.

Specific concepts that explain the mechanisms of leadership and health are few and differ substantially (e.g., [9-12]). Although all of these authors give different explanations about the mechanisms of leadership and health, all of them highlighted the importance to develop an integrated perspective, where the individual and the organizational aspects are considered. On the individual level, the leader as a person can influence health at the workplace by focusing on changing the employees' health behavior. On the organizational level, working conditions that are related to health can be identified.

A concept of health-promoting leadership that especially considers the organization's working conditions is introduced in this paper. This concept focuses on identifying specific components in leadership behavior that are able to positively influence the working conditions of employees [13]. This approach of health-promoting leadership specifically highlights the working conditions at the workplace and the leaders' behavior in changing working conditions in a health-supportive and sustainable way. Supporting a healthy working environment by focusing on the management of working conditions is an essential part in WHP [14] but is still underemphasized in leadership research [15].

In the present paper, we refer to key aspects that can be understood as the leaders' engagement to create a health-promoting workplace. The aim is to get an understanding about the concept of health-promoting leadership by investigating different facets of leadership behavior that are related to managing working conditions which support the employees' health. Identifying these leadership behaviors can support leaders in their role of health promoters. Further, we want to investigate if these facets of health-promoting leadership are related to better health at the workplace. An instrument that is able to assess these facets of health-promoting leadership behavior has been developed and is presented in this paper. Most instruments in the field of positive leadership focus on the leader as a person and specialize in identifying the specific leadership style of the leader. The instrument presented in this paper focuses on identifying the effort of leaders to manage the health-promoting working conditions from the view of the employees. In a next step, the feedback given from the employees about the leaders' effort in health-promoting behavior can enhance the leaders' ambition to improve working conditions to support a sustainable workplace.

\subsection{Leadership and Health}

Leadership behaviors can influence individual factors (employees' health behavior) and organizational factors (working conditions) which are both needed in the sense of obtaining a healthy workplace [12]. This view is also shared by Wegge, Shemla and Haslam [16] who concluded that the relationship between leadership and employee health is not restricted to the personal interaction between leader and employee. They identified four other pathways that can explain the complex relationship between leadership and employee health: system-focused action (e.g., leaders promote healthy work designs), moderating action (e.g., leaders alleviate the impact of stressors at the workplace), climate control (e.g., leaders cultivate a shared perception of health in the team), and modelling (e.g., the leader acts as a role model for health and exemplifies particular health behavior). Especially the system-focused pathway could be a sustainable way to improve health, as it involves the whole organizational environment in contributing to a healthy workplace. By addressing 
both individual and organizational components, leadership development is not restricted to single individuals. It involves the whole organization and emphasizes the organizational structures in which leaders and employees work $[9,10,17]$.

Most studies in the field of leadership and employee health focus on the direct interaction (person-focused action) between leader and employee [11,18]. The promotion of healthy working conditions (system-focused action) with the support of leadership has been little studied over the years, but is increasingly becoming a central focus of more recent research. Leaders can build policies, practices and procedures to create a safe psychosocial working climate to protect employee psychological health and safety [19]. These procedures can include managing and changing working conditions to obtain a health-promoting workplace, which is also a much more sustainable approach to change employee health in the current view of WHP $[14,20]$ and in the view of psychosocial risk assessment [21]. In psychosocial risk assessment, a safe and health-promoting workplace can be obtained by reducing working conditions that have a potential harmful effect on the employees [22]. However, the management of risks at the workplace should not only focus on the reduction of negative conditions, but also on the enhancement of conditions with desirable outcomes on performance and improvements [23].

Health-promoting leadership can be seen as a leadership behavior that is in line with concepts of WHP and risk assessment. Conceptualizations of health-promoting leadership should include the approaches within these concepts, where the creation of a healthy workplace with improved working conditions is included. In this view, health-promoting leadership means that leaders should create health-supporting working conditions and thus indirectly influence employee health.

\subsection{Key Aspects of Health-Promoting Leadership}

Health-promoting leadership should aim to create a health-promoting workplace for employees by changing the working conditions in their organizational area of influence. Leaders have an impact on these working conditions and consequently can reduce stress and enhance resources for the employees. Therefore, specific working conditions have to be identified that have an effect on employee health and can be changed with leadership.

A helpful framework to identify risk factors at the workplace that can lead to negative health-related outcomes (e.g., burnout) is the concept of the areas of worklife [24,25], where six factors are defined: workload, control, rewards, community, fairness, and values. Leaders who can change these six areas are able to influence employee health positively [4]. The six areas and the possible actions of leaders within these six areas are described briefly in the next paragraphs.

Increased workload is known to have a consistent relationship with burnout [25,26]. High workload leads to negative health-related consequences when recovery is insufficient. This imbalance of workload and recovery can lead to exhaustion and increased risk for burnout [27]. For leaders, it is possible to influence the balance of workload and recovery by designing the work structures or procedures.

Control possibilities at the workplace are important and have beneficial outcomes on health [28-30]. Control possibilities at work often depend on characteristics of the job (e.g., hierarchical position, tasks); nevertheless, it is possible to give employees their necessary control opportunities.

Insufficient reward increases the risk of burnout [18,25,31]. Therefore, reward is seen as an important part of the positive relationship between leader and employee. Leaders can create a working environment where the achieved work is appreciated and effort does not go unnoticed, thus recognizing all contributions.

Community describes the quality of social interactions-Halbesleben [32] demonstrated that positive social interactions at work reduce exhaustion. On the other hand, negative social interactions at work increase the risk of health impairments [33]. Therefore, enhancing a supportive working community and cooperative team climate should be crucial tasks for health-promoting leadership.

Fairness in rewards, procedures and treatments are aspects in the working environment that leaders can influence significantly $[34,35]$. The feeling of being treated in an unfair way can cause 
emotional exhaustion and cynicism, which again are risk factors for burnout [26]. Although sense of fairness might differ from person to person, there are some aspects that should serve as a basis for a fair working climate (e.g., distributing the organizational resources fairly or giving the same career possibilities for everyone).

A mismatch in the area of values refers to the discrepancy between the work that has to be accomplished and the personal values, and can represent a considerable risk factor for burnout [26]. Thus, experiencing a high congruence of organizational and personal values is essential for a positive working life [36]. Leaders can enhance value congruence by trying to match the employees' daily activities and career interests with the company's objectives. Leaders (and organizations) should always have a look on the congruence of the employees' values with the company's objectives.

By changing these six working conditions, leaders indirectly influence employee health by creating working conditions that can be experienced as health-promoting. This can be seen as a preventive approach to secure healthy workplaces (this approach is also more in the sense of the strategy of the European Union on healthy workplaces).

Another aspect that is more directly connected to employee health is the aspect of health awareness. Health awareness means to be aware of the basics of health at the workplace and its importance for employee well-being. Franke and Felfe [37] argued that leaders, who are looking after their own health, are more disposed to look after the health of their employees. Gurt et al. [11] also noted that leadership tasks should involve higher health awareness, like showing more responsibility for employee health, communicating about health-related topics or setting agendas for WHP. Especially in the field of WHP, leaders are able to positively influence employee health by supporting health promotion programs and policies [38]. In comparison to the other six areas, this approach of health-promoting leadership has a stronger emphasis on enhancing health at the workplace by directly focusing at the health of employees. Therefore, we see this individual-related approach as an important supplement to the other-more working condition-related—areas in our definition of health-promoting leadership.

\subsection{Development of an Instrument to Measure Health-Promoting Leadership}

To analyze health-promoting leadership and its underlying key aspects (health awareness, workload, control, reward, community, fairness, and value-fit), a questionnaire (Health-Promoting Leadership Conditions, HPLC) was developed. The questionnaire was created for two kinds of assessment-an assessment done from the employee's point of view (external assessment) and from the leader's point of view (self-assessment). The self-assessment version can be used to give comprehensive feedback to leaders by demonstrating their potential in health-promoting leadership. The external assessment done by employees is important for analyzing whether the working conditions of the employee are designed in a health-promoting way. These two versions only differ in terms of the introductory sentence: "As a leader I take care that ... ." for the self-assessment, and "My leader takes care that ..." for the external assessment.

For the HPLC, new items were created to measure health-promoting leadership. The construction of the development bases upon the six areas of worklife [25] and the concept of health awareness (see also [11,37]). For some items, the questionnaire for the areas of worklife (areas of worklife scale (AWS) [39]) was used as a basis. Using the example of the dimension reward, the item in the AWS ("My work is appreciated") was formulated in the external assessment version of the HPLC to "My leader takes care that ... work is appreciated." Here, mainly the stem of the item has been changed so that these items represent active leadership behaviors that can be assessed by employees.

Other items were newly created. For example, one item for the dimension control " . . all have the necessary scope to do their work" was newly developed. The items for workload were formulated in a positive direction to represent the health-influencing aspect of moderate workload, e.g., "there is enough time left for the work to be done." For the dimension health awareness, new items were written for the HPLC. All items are shown in Table 1. 
All items were created in a manner that they could serve for both self- and external assessment without changing the wording. Only the instruction sentence shows the difference between both versions. The questionnaire consists of 21 items (three items per dimension). A frequency scale ranging from never (0) to always (6) was used to measure the frequency of health-promoting behavior.

Both versions measure the frequency of health-promoting behavior. In the external assessment done by the employees, the employees can rate "how often" they experience health-promoting leadership behavior from their leaders. This observation of health-promoting behavior is done on an individual-level but can provide insight into the organization's culture [40].

One aim of the present study is to investigate if the seven dimensions are able to measure health-promoting leadership conditions and if the questionnaire fulfills scientific criteria for psychological assessments. In the present paper, the external assessment version is analyzed; the psychometric properties of the self-assessment version have been published by Jiménez et al. [4].

First, we expect that all seven dimensions can be assigned to a main factor:

Hypothesis 1. All seven dimensions of health-promoting leadership can be assigned to a main factor.

As the dimension health awareness overlaps with Franke and Felfe's [37] model, positive correlations between health awareness in the HPLC and their construct of health awareness are expected. For the other six HPLC-dimensions positive correlations with the HoL in the sense of convergent validity are expected.

Hypothesis 2. The dimension health awareness is positively associated with all dimensions of Franke and Felfe's [37] questionnaire about health-oriented leadership (HoL).

\subsection{Health-Influencing Conditions in Organizations}

It is important to define what aspects of health can be influenced by the organization and its leaders and what aspects cannot be supported by the organization in the view of WHP. A holistic perspective is needed, where health is understood on a physical, mental and emotional/social level [41,42]. Additionally, health has to be seen on an organizational level by focusing on the organization as a system $[31,43]$. The World Health Organization (WHO) [44] provided a definition of health in occupational settings: "A healthy workplace is one in which workers and managers collaborate to use a continual improvement process to protect and promote the health, safety and well-being of all workers and the sustainability of the workplace" (p. 6). The WHO [44] specifically state that next to health and safety concern, the organization of work and the personal resources should be considered in the development of healthy workplaces. It has to be noted that health at the workplace does not only refer to the actual physical health of the employees (e.g., physical illness or diseases), but also to the psychological or emotional aspects [45]. In WHP, health indicators at the workplace range from the employees' physical or mental health to work-related variables, such as stress caused by organizational conditions [46].

Healthy workplaces are also discussed in psychosocial risk assessment [21]. In psychosocial risk assessment, working conditions with negative effects on employee health are considered a psychosocial risk that have to be managed properly to increase a safe and healthy workplace [22]. Negative health effects in psychosocial risk assessment are usually operationalized by short-term or long-term strain outcomes, such as stress sensations or burnout [47].

The terms 'health at the workplace' and 'well-being at the workplace' are often used interchangeably but should be differentiated [31]. Well-being at the workplace encompasses all positive job-related experiences such as job satisfaction or job attachment [45]. The experience of low stress or a low burnout-risk also falls into the category of a positive job-related experience [31]. Health at the workplace, as it is stated in the concepts of WHP and psychosocial risk assessment, therefore can be seen as a more specific subdomain of well-being at the workplace. The viewpoint of building a healthy workplace by managing working conditions is in line with the definition of a sustainable 
workplace. According to Di Fabio [1], sustainable workplaces foster employee health in the sense of primary prevention, which means preventing health impairment before it can start. Sustainability means building workplaces that support the strengths and resources of employees [1], which in the short-term lowers stress and burnout and on the long-term enhances motivation and job performance, increasing the organization's competitiveness [48].

In prevention, especially the resources of the working environment play an important role as health influencing conditions [1]. This focus on resources can be found in the job demands-resources model [28] or in the model of recovery-stress balance [27,49]. Both models highlight the importance of job characteristics and their effects on employee health.

The job demands-resources model indicates that job demands and resources have an effect on employee health. Job demands are characterized by job aspects that require sustained physical or psychological effort (e.g., high work pressure, physical or emotional demands). Job resources are aspects that enable achieving work goals, decrease demands and stimulate personal growth (e.g., social support, autonomy, feedback). Job demands consume the employee's resources, therefore this approach aims to reduce job demands and promote job resources to enhance employee health which is directly in line with the ideas of WHP [7,44].

The model of recovery-stress-balance $[27,49]$ highlights the importance of recovery processes at work that aim to restore replenished resources. The balance between stress and resources gets worse if prolonged stressful situations occur together with repeated shortened recovery and a depletion of resources. This in turn can lead to higher stress and/or symptoms of burnout (e.g., exhaustion) especially if important working conditions are considered [25]. Regulating the recovery-stress-balance by replenishing resources can cancel this self-reinforcing process and restore health [49,50].

Focusing on health-influencing conditions it becomes clear that one major aspect of health-promoting leadership has to be promoting health by reducing stress and increasing resources. Employees with the abilities to adapt to the demands of work life are able to stay healthy. With health-promoting leadership, leaders can positively change working conditions and therefore indirectly influence the balance between stress and resources with their behavior.

Therefore, we expect high correlations between the dimensions of the HPLC and the experience of stress, burnout and resources at the workplace (criterion validity).

Hypothesis 3a. All dimensions of health-promoting leadership are negatively associated with stress-related working aspects and burnout.

Hypothesis $3 \mathbf{b}$. All dimensions of health-promoting leadership are positively associated with resources-related working aspects.

\section{Materials and Methods}

\subsection{Sample and Procedure}

Employee surveys were conducted in two Austrian organizations - paper-pencil surveys with questionnaires around health-promoting leadership were distributed to all employees. Additionally, the survey was available on an online-portal where interested employees filled-in an online version of these questionnaires. The link to the online-survey was advertised in the newsletter from the local chamber of commerce and was open to all interested persons in Austria. With this method, the data of 430 employees without a leadership position were collected. The first employee survey was conducted in an organization in the commerce sector. The data of 195 employees $(45.3 \%)$ were obtained in this first employee survey. The second employee survey was conducted in an organization with focus on teaching and education. This sample consisted of 166 employees (38.6\%). The remaining data of 69 employees $(16 \%)$ were obtained from the online sample and came from various organizations and industrial sectors. All employees worked in Austrian companies. As the data was collected with two 
employee surveys, confidentiality of data must be considered. Therefore, it is not possible to make detailed specifications about our sample except for gender (women: $64 \%$; men: $36 \%$ ) and age $(82 \%$ of the participants were 45 years or younger).

The approval of the ethical commission for this study was obtained as part of a comprehensive study about leadership and health-related outcomes.

\subsection{Measures}

\subsubsection{Health-Promoting Leadership Conditions (HPLC)}

The HPLC measures the seven dimensions of health-promoting leadership: health awareness, workload, control, reward, community, fairness and value-fit. Every dimension has three items which makes 21 items in total, answer scale ranges from $0=$ "never" till $6=$ "always." The questionnaire can be used as a self-assessment version for leaders and as an external assessment version for employees. In the present study, only the external assessment version was used. All items are listed in Table 1. The assignment of the items to the seven dimensions is shown in Table 2.

Table 1. Items, item shortcuts and internal consistencies of the HPLC.

\begin{tabular}{|c|c|c|}
\hline $\begin{array}{c}\text { Item } \\
\text { Shortcuts }\end{array}$ & Items My Leader Takes Care, that ... & $\begin{array}{l}\text { Item Total } \\
\text { Correlation }\end{array}$ \\
\hline HA_1 & ... the health of all employees is promoted. & 0.89 \\
\hline HA_2 & ... all employees are motivated to take care of their health. & 0.81 \\
\hline HA_3 & ... the health of the employees is highly valued. & 0.86 \\
\hline WL_1 & ... there is enough time left for the work to be done. & 0.77 \\
\hline WL_2 & ... work under high pressure is not carried out over a longer period of time. & 0.80 \\
\hline WL_3 & ... work does not significantly affect private life. & 0.69 \\
\hline CT_1 & ... the resources and scope for personal development at work can be influenced. & 0.72 \\
\hline CT_2 & ... at work autonomous and independent action can be taken. & 0.63 \\
\hline CT_3 & ... all have the necessary scope to do their work. & 0.79 \\
\hline RE_1 & ... work is appreciated. & 0.81 \\
\hline RE_2 & ... efforts do not go unnoticed. & 0.76 \\
\hline RE_3 & ... all contributions are being acknowledged. & 0.83 \\
\hline CM_1 & ... work colleagues support each other. & 0.81 \\
\hline CM_2 & ... there is a good cooperation between all work colleagues. & 0.85 \\
\hline CM_3 & ... work colleagues talk openly to each other. & 0.80 \\
\hline FA_1 & ... all resources are fairly distributed. & 0.76 \\
\hline FA_2 & ... all employees are treated in a fair manner. & 0.74 \\
\hline FA_3 & ... one's career depends on competencies and not on the connections someone has. & 0.72 \\
\hline VA_1 & ... the employees share the company's values. & 0.75 \\
\hline VA_2 & ... the employees' daily activities correspond with the company's objectives. & 0.70 \\
\hline VA_3 & ... personal career interests are in line with the objectives of the company. & 0.70 \\
\hline
\end{tabular}

Note: Answer scale 0 'never' 1 'seldom' 2 'sometimes' 3 'often' 4 'more often' 5 'very often' 6 'always'.

Table 2. Means (M), standard deviations (SD), and internal consistencies ( $\alpha$ ) of the dimensions of the HPLC.

\begin{tabular}{ccccc}
\hline Dimension & Item Shortcuts & M & SD & $\alpha$ \\
\hline Health awareness & HA_1, HA_2, HA_3 & 2.45 & 1.72 & 0.93 \\
Workload & WL_1, WL_2,WL_3 & 2.83 & 1.54 & 0.87 \\
Control & CT_1,CT_2,CT_3 & 3.51 & 1.43 & 0.84 \\
Reward & RE_1, RE_2, RE_3 & 3.05 & 1.61 & 0.90 \\
Community & CM_1,CM_2,CM_3 & 3.46 & 1.63 & 0.91 \\
Fairness & FA_1, FA_2, FA_3 & 3.17 & 1.58 & 0.86 \\
Value-fit & VA_1, VA_2, VA_3 & 3.10 & 1.46 & 0.85 \\
\hline
\end{tabular}

Note: Answer scale 0 'never' 1 'seldom' 2 'sometimes' 3 'often' 4 'more often' 5 'very often' 6 'always'.

\subsubsection{Health-Oriented Leadership (HoL)}

Health-oriented leadership was assessed with the questionnaire HoL by Franke and Felfe [37]. In this study, the external assessment version was used where employees rate the behavior of their supervisors. The questionnaire measures three different scales: awareness, values, and behavior. 
The 21 items can be answered on a 5-point-likert-scale that ranges from $1=$ "I absolutely not agree" to $5=$ "I totally agree." The HoL was only used in the online survey and not in the paper-pencil survey. Therefore, the sample for the HoL is smaller than for the other questionnaires.

\subsubsection{Maslach Burnout Inventory-General Survey German (MBI-GS-D)}

The MBI-GS [51] (German version MBI-GS-D by [52] measures burnout with three dimensions: emotional exhaustion, cynicism and personal accomplishment. The 16 items are answered on a 7-point-likert scale ranging from $0=$ "never" to $6=$ "every day." The MBI-GS-D was only used in one of the two paper-pencil surveys and in the online survey. Therefore, the sample for the MBI-GS-D is smaller than for the other questionnaires.

\subsubsection{Recovery-Stress-Questionnaire for Work (RESTQ-Work)}

The RESTQ-Work addresses different aspects of stress and resources in the past seven days/nights. The short version of the Recovery-Stress-Questionnaire for Work (RESTQ-Work/27 [53] was used. The 27 items can be categorized in six different dimensions: social emotional stress, overall recovery, loss of meaning/burnout, leisure/breaks, psychosocial resources, and work-related resources. The answer scale ranges from $0=$ "never" to $6=$ "always."

\subsection{Analysis}

In order to test the structure of the HPLC, a Structural Equation Modeling (SEM) with maximum likelihood estimation was conducted using the Analysis of Moment Structures program (AMOS) Version 21. As the chi-square analysis is very sensitive to sample size and most likely will show a significant result when analyzing 430 cases, it is common to interpret the fit indices instead. Following fit indices were taken into account: Adjusted Goodness of Fit Index (AGFI), Goodness of Fit Index (GFI), Comparative Fit Index (CFI), and Root Mean Square Error of Approximation (RMSEA). The AGFI and GFI should be greater than 0.85 and 0.90 , respectively [54]. The CFI should be greater than 0.95 [55] and the RMSEA should be 0.06 or lower to indicate a good model fit [56].

\section{Results}

\subsection{Item Analysis}

Means and standard deviations for all dimensions of the HPLC are shown in Table 2. The internal consistency assessed by Cronbach's Alpha ranges from 0.84 to 0.93 (Table 2). Item discriminations all range above 0.40 (0.63 to 0.89 ) fulfilling the minimum criteria of psychological assessments.

Intercorrelations between the dimensions of the HPLC are very high, ranging from 0.69 to 0.86 (Table 3). The highest correlation coefficients within the seven dimensions can be found when correlating community and fairness (0.87) and value-fit and fairness (0.86).

\subsection{Structural Equation Modeling (SEM)}

To analyze if the seven dimensions of health-promoting leadership can be assigned to a higher order factor, the higher-order factor model was compared to different models.

Unidimensional model. First, a unidimensional (one-factor) model was tested. This model provided a marginal fit to the data $\left(\chi^{2}(184)=959.000, p<0.001\right)$. The fit indices are depicted in Table 4 .

First order model (uncorrelated). The next model consisted of seven first-order factors which were uncorrelated. This model showed a bad fit $\left(\chi^{2}(184)=3213.897, p<0.001\right)$ with all fit indices below their respective thresholds (Table 4).

First order model (correlated). Next, we tested a model with seven correlated first-order factors. This model showed a very good fit $\left(\chi^{2}(163)=426.059, p<0.001\right)$ with good fit indices (Table 4$)$. It seems that this multidimensional model provides a better description of the relationships between all items than the unidimensional model or the uncorrelated first order model. 
Table 3. Correlations between the dimensions of the HPLC, HoL, RESTQ-Work and MBI-GS-D.

\begin{tabular}{|c|c|c|c|c|c|c|c|c|c|c|c|c|c|c|c|c|c|c|}
\hline Dimension & $\begin{array}{c}\text { HPLC: } \\
\text { Health } \\
\text { Awareness }\end{array}$ & $\begin{array}{c}\text { HPLC: } \\
\text { Workload }\end{array}$ & $\begin{array}{l}\text { HPLC: } \\
\text { Control }\end{array}$ & $\begin{array}{l}\text { HPLC: } \\
\text { Reward }\end{array}$ & $\begin{array}{c}\text { HPLC: } \\
\text { Community }\end{array}$ & $\begin{array}{c}\text { HPLC: } \\
\text { Fairness }\end{array}$ & $\begin{array}{l}\text { HPLC: } \\
\text { Value-Fit }\end{array}$ & $\begin{array}{c}\text { HoL: } \\
\text { Awareness }\end{array}$ & $\begin{array}{l}\text { HoL: } \\
\text { Values }\end{array}$ & $\begin{array}{c}\text { HoL: } \\
\text { Behavior }\end{array}$ & $\begin{array}{c}\text { restq-W: } \\
\text { Social } \\
\text { Emotional } \\
\text { Stress } \\
\end{array}$ & $\begin{array}{l}\text { RESTQ-W: } \\
\text { Overall } \\
\text { Recovery }\end{array}$ & $\begin{array}{l}\text { RESTQ-W: Loss } \\
\text { of Meaning/ } \\
\text { Burnout }\end{array}$ & $\begin{array}{l}\text { RESTQ-W: } \\
\text { Leisure/ } \\
\text { Breaks }\end{array}$ & $\begin{array}{c}\text { RESTQ-W: } \\
\text { Psycho- } \\
\text { Social } \\
\text { Resources }\end{array}$ & $\begin{array}{c}\text { RESTQ-W: } \\
\text { Work- } \\
\text { Related } \\
\text { Resources }\end{array}$ & $\begin{array}{l}\text { MBI-GS-D: } \\
\text { Emotional } \\
\text { Exhaustion }\end{array}$ & $\begin{array}{c}\text { MBI-GS-D: } \\
\text { Personal } \\
\text { Accomp- } \\
\text { Lishment } \\
\end{array}$ \\
\hline \multicolumn{19}{|l|}{ HPLC: health awareness } \\
\hline HPLC: workload & 0.76 ** & & & & & & & & & & & & & & & & & \\
\hline HPLC: control & 0.70 ** & $0.74^{* *}$ & & & & & & & & & & & & & & & & \\
\hline HPLC: reward & $0.77 * *$ & 0.75 ** & 0.84 ** & & & & & & & & & & & & & & & \\
\hline HPLC: community & $0.69 * *$ & 0.72 ** & $0.73^{\text {** }}$ & $0.77^{* *}$ & & & & & & & & & & & & & & \\
\hline HPLC: fairness & $0.78^{* *}$ & $0.80^{* *}$ & $0.82^{* * *}$ & $0.87^{* * *}$ & $0.78^{* *}$ & & & & & & & & & & & & & \\
\hline HPLC: value-fit & 0.76 ** & $0.71 * *$ & $0.81^{* *}$ & $0.82^{* *}$ & $0.76 * *$ & 0.86 ** & & & & & & & & & & & & \\
\hline HoL: awareness & $0.65^{* *}$ & $0.63 * *$ & $0.51^{* *}$ & $0.65^{* *}$ & $0.63^{* *}$ & $0.68^{* *}$ & $0.68^{* *}$ & & & & & & & & & & & \\
\hline HoL: values & 0.76 ** & $0.61^{* *}$ & $0.57^{* * *}$ & $0.61^{* * *}$ & $0.49 * *$ & $0.69 * *$ & $0.58^{* *}$ & $0.65^{* *}$ & & & & & & & & & & \\
\hline HoL: behavior & $0.84^{* *}$ & $0.70^{* *}$ & $0.54^{* * *}$ & $0.61^{* *}$ & 0.52 ** & $0.64^{* *}$ & 0.58 ** & $0.67 * *$ & $0.78^{\text {** }}$ & & & & & & & & & \\
\hline $\begin{array}{l}\text { RESTQ-W: social } \\
\text { emotional stress }\end{array}$ & $-0.23 * *$ & -0.31 ** & -0.35 ** & -0.31 ** & $-0.23 * *$ & -0.36 ** & $-0.29 * *$ & -0.13 & -0.09 & -0.12 & & & & & & & & \\
\hline $\begin{array}{l}\text { RESTQ-W: overall } \\
\text { recovery }\end{array}$ & 0.25 ** & $0.34^{* *}$ & $0.33^{* *}$ & $0.28^{* *}$ & $0.20 * *$ & 0.31 ** & $0.26 * *$ & $0.40^{*}$ & $0.48^{* *}$ & $0.35 *$ & -0.56 ** & & & & & & & \\
\hline $\begin{array}{l}\text { RESTQ-W: loss of } \\
\text { meaning/burnout }\end{array}$ & -0.35 ** & $-0.48 *$ & -0.47 ** & $-0.44^{* *}$ & -0.36 ** & $-0.48 * *$ & $-0.42^{* *}$ & -0.48 ** & -0.28 & $-0.34 *$ & $0.74^{* *}$ & $-0.49 * *$ & & & & & & \\
\hline $\begin{array}{c}\text { RESTQ-W: } \\
\text { leisure/breaks }\end{array}$ & 0.30 ** & $0.41^{* *}$ & $0.38^{* *}$ & $0.31^{* *}$ & $0.21^{* *}$ & $0.31^{* *}$ & $0.25 *$ & $0.59 * *$ & $0.54 *$ & $0.56^{* *}$ & -0.47 ** & $0.63^{* *}$ & -0.49 ** & & & & & \\
\hline $\begin{array}{c}\text { RESTQ-W: psychosocial } \\
\text { resources }\end{array}$ & 0.33 ** & $0.31^{* *}$ & 0.35 ** & $0.36^{* *}$ & 0.50 ** & 0.36 ** & $0.34 * *$ & $0.43^{* *}$ & 0.28 & 0.28 & -0.09 & $0.26 *$ & $-0.17^{* *}$ & $0.29 * *$ & & & & \\
\hline $\begin{array}{l}\text { RESTQ-W: work-related } \\
\text { resources }\end{array}$ & $0.47^{* *}$ & $0.44^{* *}$ & $0.66 * *$ & $0.58^{* *}$ & $0.44^{* *}$ & $0.57 * *$ & $0.54 *$ & 0.52 ** & $0.47^{* *}$ & $0.47^{* *}$ & $-0.33^{* *}$ & $0.46^{* *}$ & -0.42 ** & $0.41^{* *}$ & 0.39 ** & & & \\
\hline $\begin{array}{l}\text { MBI-GS-D: emotional } \\
\text { exhaustion }\end{array}$ & $-0.25^{* *}$ & $-0.37^{* *}$ & $-0.31^{* *}$ & $-0.32^{\text {** }}$ & -0.32 ** & -0.36 ** & $-0.29 * *$ & -0.29 & -0.30 & -0.20 & 0.55 ** & $-0.42 * *$ & 0.66 ** & -0.53 ** & $-0.18^{*}$ & $-0.29 * *$ & & \\
\hline MBI-GS-D: cynicism & $-0.40^{* *}$ & $-0.41^{* *}$ & -0.53 ** & $-0.57^{* *}$ & $-0.51^{* *}$ & -0.58 ** & -0.52 ** & $-0.40^{*}$ & $-0.39 *$ & -0.23 & $0.48^{* *}$ & $-0.36 * *$ & 0.70 ** & $-0.32 * *$ & $-0.27 * *$ & $-0.55^{* *}$ & $0.58^{* *}$ & \\
\hline $\begin{array}{c}\text { MBI-GS-D: personal } \\
\text { accomplishment }\end{array}$ & 0.23 ** & $0.22 * *$ & 0.37 ** & $0.30^{* *}$ & 0.25 ** & 0.31 ** & $0.34 * *$ & 0.24 & 0.32 & 0.18 & -0.30 ** & $0.44^{* *}$ & -0.36 ** & $0.30^{* *}$ & $0.25^{* *}$ & $0.58^{* *}$ & -0.18 ** & -0.42 ** \\
\hline
\end{tabular}

Note: HPLC: $\mathrm{N}=430$, HoL: $\mathrm{N}=64$, RESTQ-Work: $\mathrm{N}=400$, MBI-GS-D: $\mathrm{N}=211$; correlations important for convergent validity are printed in bold; * correlation significant ( $p<0.05$ ); $* *$ correlation significant $(p<0.01)$. 
Seven-factor higher order model. Finally, we tested the seven-factor higher order model, where all seven dimensions of health-promoting leadership are combined to one higher order factor. This model showed a very good fit to the data $\left(\chi^{2}(177)=482.880, p<0.001\right.$; Table 4$)$. All regression coefficients are significant $(p<0.001)$ and range between 0.67 and 0.94 (Figure 1).

To compare the fit of the seven-factor higher order model with the first order model, the target coefficient (T) by Marsh [57] and Marsh and Hocevar [58] was calculated. The target coefficient represents the ratio of the chi-square of a first order model to the chi-square of the seven-factor higher order model. A target coefficient close to 1 indicates that the higher order model can effectively explain the correlation between the first-order factors [58]. In the present analysis, the target coefficient is 0.88 , indicating that the higher order factor of health-promoting leadership accounts for a large proportion of the covariation among the first-order factors. A conceptually similar indicator ("target coefficient 2," T2) also indicates the goodness of fit for a higher order model. In contrast to T, the zero-point is defined by the fit of the first-order model with uncorrelated factors. In our case, T2 is also very high (0.98).

Table 4. Dimensions, means, standard deviations, internal consistencies, item total correlations and example items of the HPLC.

\begin{tabular}{|c|c|c|c|c|c|c|c|c|c|}
\hline Model & $x^{2}$ & df & $p$ & AGFI & GFI & CFI & RMSEA & $\mathbf{T}$ & T2 \\
\hline unidimensional model & 959.000 & 184 & $<0.001$ & 0.780 & 0.825 & 0.906 & 0.099 & & \\
\hline first-order model (uncorrelated) & 3213.897 & 184 & $<0.001$ & 0.322 & 0.460 & 0.634 & 0.196 & & \\
\hline first-order model (correlated) & 426.059 & 163 & $<0.001$ & 0.873 & 0.910 & 0.968 & 0.061 & & \\
\hline seven-factor with higher order factor model & 482.880 & 177 & $<0.001$ & 0.869 & 0.899 & 0.963 & 0.063 & 0.882 & 0.979 \\
\hline
\end{tabular}

Note: $\chi^{2} \ldots$ Chi-Square; $\mathrm{df} \ldots$ degrees of freedom; $\mathrm{T} .$. target coefficient (represents the ratio of the chi-square of the first-order model to the chi-square of the higher order model); T2 ... target coefficient 2 (represents the ratio of the difference between the chi-square of the uncorrelated first-order model and the first-order model to the difference between the chi-square of the uncorrelated first-order model and the higher order model).

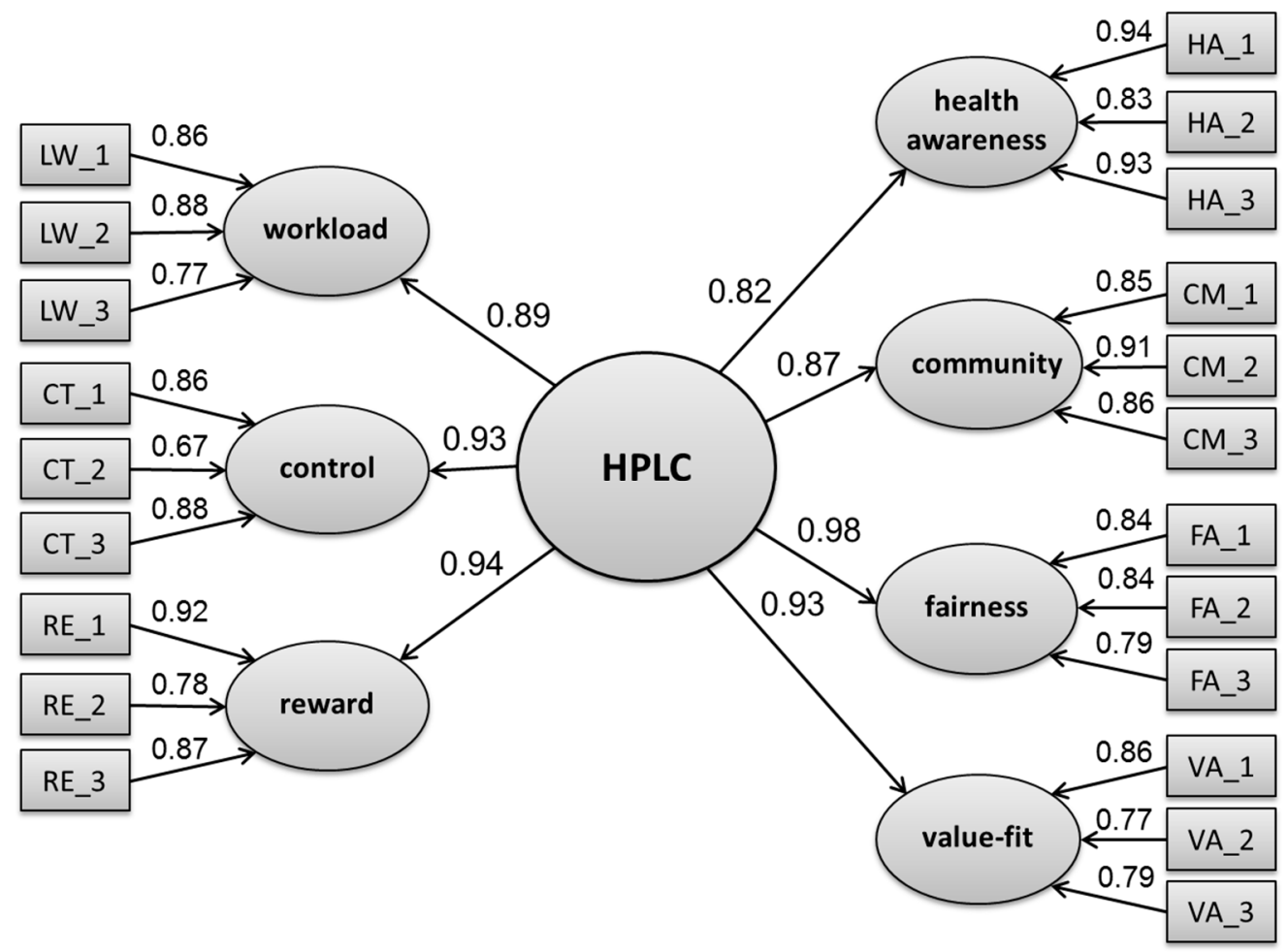

Figure 1. Regression coefficients for the HPLC model ( $N=430$; all regression coefficient significant with $p<0.001$ ). 


\subsection{Validity Analysis}

Analyzing convergent validity, the dimensions of the HoL were correlated with the dimensions of the HPLC. The results show high coefficients $(0.49-0.84)$, having the highest correlations between health awareness (HPLC) and behavior (HoL) (0.84) as well as values (HoL) (0.76). All correlation coefficients for convergent validity are in Table 3 and printed in bold.

In the sense of criterion validity, the relation between health-promoting leadership and stress (RESTQ-Work) and burnout (MBI-GS-D) were analyzed. Regarding stress, the correlation between the dimensions of HPLC and RESTQ-Work show expected results, having moderate negative coefficients with social emotional stress $(-0.23$ to -0.36$)$ and high negative coefficients with loss of meaning/burnout ( -0.35 to -0.48 ). For the MBI-GS-D, the highest negative correlations can be found with cynicism $(-0.40$ to -0.58$)$.

For the resources-related dimensions of the RESTQ-Work, highest coefficients can be found when correlating control (HPLC) and work-related resources (RESTQ-Work) (0.66), as well as community (HPLC) and psychosocial resources (RESTQ-Work) (0.50). All results are shown in Table 3.

\section{Discussion}

The aim of the present study was to identify key aspects of health-promoting leadership that are able to influence employee health positively. We especially focus on leadership behavior that aims to changing the working conditions to indirectly support the employees' health. An instrument with 21 items (HPLC) has been constructed that measures seven dimensions of health-promoting leadership: health awareness, workload, control, reward, community, fairness, and value-fit. The Cronbach's Alpha for all seven dimensions can be regarded as high, the item discriminations are within the accepted thresholds.

We hypothesized that all seven dimensions of health-promoting leadership can be assigned to a main factor. The tested model shows an acceptable fit by having the CFI and RMSEA succeeding the acceptable thresholds. In addition, the target coefficients T and T2 [57] support the presence of a higher order factor of health-promoting leadership. Intercorrelations between the seven dimensions show high coefficients. The highest intercorrelations result by correlating reward and fairness as well as community and fairness. Looking at the items of the dimensions, reward is specified with items like “( ... ) efforts do not go unnoticed" or "( . . ) all contributions are being acknowledged." So basically, reward means acknowledging dedication and performance of employees in financial and non-financial ways. Fairness implies being treated fairly regarding decisions and procedures and that everything should be shared correctly. In the HPLC, fairness is characterized with items like " $(\ldots$ ) all resources are fairly distributed." Community is the overall quality of social interaction at work, characterized with items like " $(\ldots)$ ) work colleagues support each other." The definition and items of all three dimensions are clearly different. Nevertheless, it could be argued that insufficient reward or negative social interactions might lead to a feeling of unfair treatment. Another explanation would be that a leader that ensures a fair working environment also gives the right reward and takes care of a positive working community.

Although the dimensions can be assigned to a main factor of health-promoting leadership, distinguishing the dimensions has significant practical implications: With seven dimensions, leaders and organizations are able to get a more detailed feedback about health-promoting leadership conditions, which can be used to create specific interventions, which is important in the process of WHP. Of course, the high correlation between fairness and community as well as fairness and reward should be examined in further studies.

As the dimension health awareness in the construct health-promoting leadership is similar to the ideas of Franke and Felfe [37] we expected high positive correlations between health awareness of the HPLC and the dimensions of Franke and Felfe's [37] questionnaire HoL (Hypothesis 2). All dimensions of the HoL show high positive correlations with health awareness, having the highest coefficients between health awareness (HPLC) and behavior (HoL) and values (HoL). Besides these 
high correlations, high positive coefficients between the HoL and all other dimensions of the HPLC could be found. This means in the sense of convergent validity that both questionnaires depict attributes of health-promoting leadership. Beside this similarity, both questionnaires have important differences. The HoL highlights the individual aspect by identifying attitudes and behavior of the leader. The HPLC focuses on the indirect approach towards employee health by changing working conditions to support a health-promoting workplace. This conceptual difference is apparent when looking at the correlations between control or community and the scales of the HoL. These correlations are much lower than the correlations between health awareness and the scales of the HoL. Therefore, we conclude that the aspect of control opportunities and creating a community between colleagues is more apparent in the HPLC.

The third research question was the relation between health-promoting leadership and the experience of stress, burnout and resources at the workplace. Focusing on our concept of employee health, one major aspect of health-promoting leadership has to be promoting employee health by reducing stress and increasing resources. Therefore, we expected high correlations between all dimensions of the HPLC and the experience of stress and resources at the workplace.

To analyze the relation between health-promoting leadership and experience of stress, the HPLC was correlated with the stress-related dimensions of the RESTQ-Work and the scales of the MBI-GS-D. As expected, the correlations are highly negative, especially with loss of meaning/burnout (RESTQ-Work) and cynicism (MBI-GS-D). This supports the assumption that health-promoting leadership strategies are negatively related to employee stress and burnout. This result is in line with the concept of the areas of worklife, where a mismatch in the six areas workload, control, reward, community, fairness, and values is seen as a major risk factor for burnout [25]. However, causal interpretations must be done with high caution as correlations and cross-sectional data does not allow interpreting results causally.

Analyzing the relationships between health-promoting leadership and resources at the workplace, the HPLC was correlated with the resources-related dimensions of the RESTQ-Work. The results show that the work-related resources dimension is highly positively correlated with control, and psychosocial resources shows a high positive relation with community-which can be stated as an argument for a high criterion validity of the HPLC. Furthermore, the leisure/breaks dimension has the highest correlation coefficient with workload, which is also an expected outcome in the sense of convergent validity.

The results show that leaders can support in developing a health-promoting workplace with their leadership behavior. It should be noted, that leadership behavior is not the only aspect to support a health-promoting workplace, although it is a very important one. Leaders can be promoters of a healthy workplace and forward their health-promoting influence in a top-down process to lower levels of management and their subordinates [19]. However, the organizational culture influences the leadership behavior by its guidelines, practices and values [59]. Therefore, leaders can only act when the organizational culture allows them to. On the other hand, leaders affect the organizational culture with their personal values and behavior [60]. In an optimal way, a health-promoting leadership culture is established when all persons in the organization work together to obtain a healthy workplace. In addition, this would be the best way for achieving a sustainable health-promoting workplace that includes the positive long-term effects on motivation and performance.

This study was a cross-sectional study with the data collected at one measurement point. Although it seems plausible that leadership strategies have an effect on health and well-being of employees, a causal interpretation only can be done with longitudinal data.

A broader view of leadership also should include the complex aspects of organizations and their members especially as the leader-member interaction influences each other in feedback loops $[15,61]$. An interesting side aspect of this more systemic or cybernetic view of the leader in the context of the whole organizational culture can be seen in the possible outcome of a "resilient organization" when safety at the workplace is in the focus [61-64]. Especially here the organization must be seen 
as the source of the possible leadership culture, as stated by Leveson, "Leadership creates culture which drives behavior," [65] (p. 177). Therefore, the approach of modifying working conditions with leadership is only possible in the frame of the corresponding culture of the organization.

To obtain a sample that is big enough to analyze our research question with SEM, three samples were combined: two employee surveys and one online study, all conducted at the same time. A problem that might occur when merging different samples is obtaining an inconsistent data set. By analyzing the demographic data of all three samples, we can see that gender and age of the participants are similarly distributed in all three data sets. Therefore, it seems that combining the samples into one data set is legitimate.

In addition, a matching of leaders and their employees was not possible in this study. Further studies are planned and will take a look if both leaders and employees agree on the measure of the seven health-promoting leadership dimensions. A matching of employees and their direct supervisors is also favored when investigating the possible transfer or spill-over effect. Then the assumption if the health status of supervisors affects the well-being of employees could be proved.

\section{Conclusions}

The present study introduces a questionnaire (Health-Promoting Leadership Conditions, HPLC) that measures seven dimensions of health-promoting leadership: health awareness, workload, control, reward, community, fairness and value-fit. The questionnaire offers the possibility to learn more about the working conditions of the organization that can be changed by the leaders' behavior. The indicated behavior assessed by the questionnaire can give a feedback to show the potentials of leaders but also, and more important, can suggest fields of improvement and needs for action for the organization. Therefore, the results of the questionnaire will not only help employees, but also the whole organization to improve their leadership culture by identifying critical aspects of organizational workplace conditions. This is a more preventive approach to employee health and supports creating a sustainable workplace. Assessing health-promoting leadership by using the self-assessment of leaders and the external assessment of employees in one organization and aggregating both scores could provide a first insight into the organizational climate and even the whole organizational culture. The assessment of health-promoting leadership could be implemented in the organization diagnostics phase of a WHP process. By identifying these organizational risk factors, prevention and intervention methods to maintain and increase the health of employees can be developed in an efficient way and focuses to the goals of reaching a sustainable workplace.

Acknowledgments: This publication was printed with the financial support of the University of Graz.

Author Contributions: All authors developed the questionnaire Health-Promoting Leadership Conditions (HPLC). P.J. and A.B. formulated the objectives of the study. P.J. designed the method and supervised the data assessment. B.W. and P.J. carried out the data assessment. A.B. and B.W. carried out the data analysis. A.B. and P.J. wrote the first draft of the paper. All authors reflected on the results and discussion.

Conflicts of Interest: The authors declare no conflict of interest.

\section{References}

1. Di Fabio, A. The Psychology of Sustainability and Sustainable Development for Well-Being in Organizations. Front. Psychol. 2017, 8, 1534. [CrossRef] [PubMed]

2. Suriyankietkaew, S.; Avery, G. Sustainable Leadership Practices Driving Financial Performance. Empirical Evidence from Thai SMEs. Sustainability 2016, 8, 327. [CrossRef]

3. Swerissen, H.; Crisp, B.R. The sustainability of health promotion interventions for different levels of social organization. Health Promot. Int. 2004, 19, 123-130. [CrossRef] [PubMed]

4. Jiménez, P.; Winkler, B.; Dunkl, A. Creating a healthy working environment with leadership: The concept of health-promoting leadership. Int. J. Hum. Resour. Manag. 2017, 28, 2430-2448. [CrossRef]

5. Atwater, L.E.; Brett, J.F.; Charles, A.C. Multisource feedback: Lessons learned and implications for practice. Hum. Resour. Manag. 2007, 46, 285-307. [CrossRef] 
6. Seifert, C.F.; Yukl, G. Effects of repeated multi-source feedback on the influence behavior and effectiveness of managers. A field experiment. Leadersh. Q. 2010, 21, 856-866. [CrossRef]

7. European Network for Workplace Health Promotion (ENWHP). Luxembourg Declaration on Workplace Health Promotion in the European Union. Available online: http://www.enwhp.org/fileadmin/rsdokumente/dateien/Luxembourg_Declaration.pdf (accessed on 27 September 2017).

8. Kelloway, E.K.; Barling, J. Leadership development as an intervention in occupational health psychology. Work Stress 2010, 24, 260-279. [CrossRef]

9. Anderson, D.; Plotnikoff, R.C.; Raine, K.; Barrett, L. Development of measures of individual leadership for health promotion. Leadersh. Health Serv. 2005, 18, 1-11. [CrossRef]

10. Eriksson, A.; Axelsson, R.; Axelsson, S. Health promoting leadership-Different views of the concept. Work 2011, 40, 75-84. [CrossRef] [PubMed]

11. Gurt, J.; Schwennen, C.; Elke, G. Health-specific leadership: Is there an association between leader consideration for the health of employees and their strain and well-being? Work Stress 2011, 25, 108-127. [CrossRef]

12. Hewison, A.; Griffiths, M. Leadership development in health care: A word of caution. J. Health Organ. Manag. 2004, 18, 464-473. [CrossRef] [PubMed]

13. Dunkl, A.; Jiménez, P.; Šarotar-Žižek, S.; Milfelner, B.; Kallus, K.W. Similarities and differences of health-promoting leadership and transformational leadership. Naše Gospod. 2015, 61, 3-13. [CrossRef]

14. Semmer, N. Job stress interventions and the organization of work. Scand. J. Work Environ. Health 2006, 32, 515-527. [CrossRef] [PubMed]

15. Rigotti, T.; Holstad, T.J.; Mohr, G.; Stempel, C.R.; Hansen, E.N.; Loeb, C.; Otto, K.; Kinnunen, U.; Perko, K. Rewarding and Sustainable Health-Promoting Leadership; Bundesanstalt für Arbeitsschutz und Arbeitsmedizin (BAuA): Dortmund/Berlin/Dresden, Germany, 2014.

16. Wegge, J.; Shemla, M.; Haslam, A. Leader behavior as a determinant of health at work: Specification and evidence of five key pathways. Ger. J. Hum. Resour. Manag. 2014, 28, 6-23. [CrossRef]

17. Skarholt, K.; Blix, E.H.; Sandsund, M.; Andersen, T.K. Health promoting leadership practices in four Norwegian industries. Health Promot. Int. 2015, 31, 936-945. [CrossRef] [PubMed]

18. Skakon, J.; Nielsen, K.; Borg, V.; Guzman, J. Are leaders' well-being, behaviours and style associated with the affective well-being of their employees? A systematic review of three decades of research. Work Stress 2010, 24, 107-139. [CrossRef]

19. Law, R.; Dollard, M.F.; Tuckey, M.R.; Dormann, C. Psychosocial safety climate as a lead indicator of workplace bullying and harassment, job resources, psychological health and employee engagement. Accid. Anal. Prev. 2011, 43, 1782-1793. [CrossRef] [PubMed]

20. Goldgruber, J.; Ahrens, D. Effectiveness of workplace health promotion and primary prevention interventions: A review. J. Public Health 2010, 18, 75-88. [CrossRef]

21. International Labour Office (ILO). Report of the Joint International Labour Office and World Health Organization on Occupational Health. In Psychosocial Factors at Work: Recognition and Control; International Labour Office: Geneva, Switzerland, 1986.

22. Leka, S.; Jain, A.; Cox, T.; Kortum, E. The Development of the European Framework for Psychosocial Risk Management: PRIMA-EF. J. Occup. Health 2011, 53, 137-143. [CrossRef] [PubMed]

23. Aven, T.; Krohn, B.S. A new perspective on how to understand, assess and manage risk and the unforeseen. Reliab. Eng. Syst. Saf. 2014, 121, 1-10. [CrossRef]

24. Leiter, M.P.; Maslach, C. Six areas of worklife: A model of the organizational context of burnout. J. Health Hum. Serv. Adm. 1999, 21, 472-489. [PubMed]

25. Maslach, C.; Leiter, M.P. Early Predictors of Job Burnout and Engagement. J. Appl. Psychol. 2008, 93, 498-512. [CrossRef] [PubMed]

26. Maslach, C.; Schaufeli, W.B.; Leiter, M.P. Job Burnout. Annu. Rev. Psychol. 2001, 52, 397-422. [CrossRef] [PubMed]

27. Jiménez, P.; Kallus, K.W. Stress and Recovery of Social Care Professionals: Development of a screening version of the Recovery-Stress-Questionnaire for Work. In Change and Quality in Human Service Work; Korunka, C., Hoffmann, P., Eds.; Hampp: Munich, Germany, 2005; pp. 311-323.

28. Bakker, A.B.; Demerouti, E.; Euwema, M.C. Job Resources Buffer the Impact of Job Demands on Burnout. J. Occup. Health Psychol. 2005, 10, 170-180. [CrossRef] [PubMed] 
29. Karasek, R.; Theorell, T. Healthy Work: Stress, Productivity, and the Reconstruction of Working Life; Basic Books: New York, NY, USA, 1990.

30. Nahrgang, J.; Morgeson, F.; Hofmann, D. Safety at work: A meta-analytic investigation of the link between job demands, job resources, burnout, engagement, and safety outcomes. J. Appl. Psychol. 2011, 96, 71-94. [CrossRef] [PubMed]

31. Grawitch, M.J.; Gottschalk, M.; Munz, D.C. The Path to a Healthy Workplace: A Critical Review Linking Healthy Workplace Practices, Employee Well-being, and Organizational Improvements. Consult. Psychol. J. Pract. Res. 2006, 58, 129-147. [CrossRef]

32. Halbesleben, J.R.B. Sources of Social Support and Burnout: A Meta-Analytic Test of the Conservation of Resources Model. J. Appl. Psychol. 2006, 91, 1134-1145. [CrossRef] [PubMed]

33. Lim, S.; Cortina, L.M.; Magley, V.J. Personal and Workgroup Incivility: Impact on Work and Health Outcomes. J. Appl. Psychol. 2008, 93, 95-107. [CrossRef] [PubMed]

34. Forret, M.; Love, M.S. Employee justice perceptions and coworker relationships. Leadersh. Organ. Dev. J. 2008, 29, 248-260. [CrossRef]

35. Robbins, J.M.; Ford, M.T.; Tetrick, L.E. Perceived Unfairness and Employee Health: A Meta-Analytic Integration. J. Appl. Psychol. 2012, 97, 235-272. [CrossRef] [PubMed]

36. Leiter, M.P.; Gascón, S.; Martínez-Jarreta, B. Making Sense of Work Life: A Structural Model of Burnout. J. Appl. Soc. Psychol. 2010, 40, 57-75. [CrossRef]

37. Franke, F.; Felfe, J. Diagnose gesundheitsförderlicher Führung-Das Instrument Health oriented leadership [Diagnosis of health-promoting leading culture-The instrument health oriented leadership]. In Fehlzeitenreport 2011 Schwerpunkt Führung und Gesundheit [Absenteeism Report 2011 Focus Leadership and Health]; Badura, B., Ducki, A., Schröder, H., Klose, J., Macco, K., Eds.; Springer: Heidelberg, Germany, 2011; pp. 3-13.

38. Milner, K.; Greyling, M.; Goetzel, R.; Da Silva, R.; Kolbe-Alexander, T.; Patel, D.; Nossel, C.; Beckowski, M. The relationship between leadership support, workplace health promotion and employee wellbeing in South Africa. Health Promot. Int. 2015, 30, 514-522. [CrossRef] [PubMed]

39. Leiter, M.P.; Maslach, C. The Areas of Worklife Survey Manual, 4th ed.; Centre for Organizational Research \& Development: Wolfville, NS, USA, 2006.

40. Komljenovic, D.; Loiselle, G.; Kumral, M. Organization: A new focus on mine safety improvement in a complex operational and business environment. Int. J. Min. Sci. Technol. 2017, 27, 617-625. [CrossRef]

41. Antonovsky, A. Salutogenese: Zur Entmystifizierung der Gesundheit [Salutogenesis. Unraveling the Mystery of Health]; dgvt-Verlag: Tübingen, Germany, 1997.

42. Kelloway, K.E.; Day, A.L. Building Healthy Workplaces: What we know so far. Can. J. Behav. Sci. 2005, 37, 223-235. [CrossRef]

43. Shain, M.; Kramer, D.M. Health promotion in the workplace: Framing the concept; reviewing the evidence. Occup. Environ. Med. 2004, 61, 643-648. [CrossRef] [PubMed]

44. World Health Organization. Healthy Workplaces: A Model for Action: For Employers, Workers, Policy-Makers and Practitioners; WHO Press: Geneva, Switzerland, 2010.

45. Danna, K.; Griffin, R.W. Health and Well-Being in the Workplace. A Review and Synthesis of the Literature. J. Manag. 1999, 25, 357-384. [CrossRef]

46. Aust, B.; Ducki, A. Comprehensive health promotion interventions at the workplace: Experiences with health circles in Germany. J. Occup. Health Psychol. 2004, 9, 258-270. [CrossRef] [PubMed]

47. Demerouti, E.; Bakker, A.; Nachreiner, F.; Ebbinghaus, M. From mental strain to burnout. Eur. J. Work Organ. Psychol. 2002, 11, 423-441. [CrossRef]

48. Peiro, J.M.; Ayala, Y.; Tordera, N.; Lorente, L.; Rodriguez, I. Sustainable well-being at work: A review and reformulation. Pap. Psicól. 2014, 35, 5-14.

49. Kallus, K.W. Stress and Recovery: An Overview. In The Recovery-Stress Questionnaires: User Manual; Kallus, K.W., Kellmann, M., Eds.; Pearson Assessment: Frankfurt, Germany, 2016; pp. 27-48.

50. Kallus, K.W.; Kellmann, M. Burnout in Athletes and Coaches. In Emotions in Sports; Hanin, Y.L., Ed.; Human Kinetics: Champaign, IL, USA, 2000; pp. 209-230, ISBN 9780880118798.

51. Schaufeli, W.B.; Leiter, M.P.; Maslach, C.; Jackson, S.E. Maslach Burnout Inventory-General Survey (MBI-GS). In Maslach Burnout Inventory Manual; Maslach, C., Jackson, S.E., Leiter, M.P., Eds.; Consulting Psychologists Press: Palo Alto, CA, USA, 1996; pp. 208-212, ISBN 9789996345777. 
52. Büssing, A.; Glaser, J. Managerial Stress und Burnout. A Collaborative International Study (CISMS). Die Deutsche Untersuchung (Bericht Nr. 44); Technische Universität: München, Germany, 1998.

53. Jiménez, P.; Kallus, W.K. EBF-Work (27) [RESTQ-Work (27)]; Pearson Assessment: Frankfurt, Germany, 2016.

54. Schermelleh-Engel, K.; Moosbrugger, H.; Müller, H. Evaluating the Fit of Structural Equation Models: Tests of Significance and Descriptive Goodness-of-Fit Measures. Meth. Psychol. Res. Online 2003, 8, 23-74.

55. Beauducel, A.; Wittmann, W.W. Simulation Study on Fit Indexes in CFA Based on Data with Slightly Distorted Simple Structure. Struct. Equ. Model. 2005, 12, 41-75. [CrossRef]

56. Hu, L.; Bentler, P.M. Cutoff criteria for fit indexes in covariance structure analysis: Conventional criteria versus new alternatives. Struct. Equ. Model. 1999, 6, 1-55. [CrossRef]

57. Marsh, H.W. The hierarchical structure of self-concept and the application of hierarchical confirmatory factor analysis. J. Educ. Meas. 1987, 24, 17-39. [CrossRef]

58. Marsh, H.W.; Hocevar, D. Application of Confirmatory Factor Analysis to the Study of Self-Concept: Firstand Higher Order Factor Models and Their Invariance Across Groups. Psychol. Bull. 1985, 97, 562-582. [CrossRef]

59. Tsai, Y. Relationship between organizational culture, leadership behavior and job satisfaction. BMC Health Serv. Res. 2011, 11, 98. [CrossRef] [PubMed]

60. Aitken, P. Walking the talk: The nature and role of leadership culture within organisation culture/s. J. Gen. Manag. 2007, 32, 17-37. [CrossRef]

61. Day, D.V. Leadership development: A review in context. Leadersh. Q. 2011, 11, 581-613. [CrossRef]

62. Hollnagel, E. Resilience engineering and the built environment. Build. Res. Inf. 2014, 42, 221-228. [CrossRef]

63. Schwarz, M.; Kallus, K.W.; Jimenez, P. Organisationale Resilienz und Sicherheitsverhalten in der Flugsicherung: Empirische Untersuchung von individuellen und tätigkeitsspezifischen Zusammenhängen [Organizational resilience and safety behavior in air traffic control: An empirical examination of individual and activity-specific correlates]. In Resilienz in Organisationen Stärken. Vorbeugung und Bewältigung von kritischen Situationen [Strenghtening Reslience in Organizations. Prevention and Coping in Critical Situations]; Bargstedt, U., Horn, G., van Vegten, A., Eds.; Verlag für Polizeiwissenschaft: Frankfurt, Germany, 2014; pp. 47-62, ISBN 978-3866763937.

64. Weick, K.E. The Collapse of Sensemaking in Organizations: The Mann Gulch Disaster. Adm. Sci. Q. 1993, 38, 628-652. [CrossRef]

65. Leveson, N.G. Engineering a Safer World: Systems Thinking Applied to Safety; Engineering Systems; MIT Press: Cambridge, MA, USA, 2011. 